\title{
Demographic and Socioeconomic Disparity in Knowledge About Tuberculosis in Inner Mongolia, China
}

\author{
${ }^{1}$ University of Tsukuba Faculty of Medicine, Tsukuba, Japan \\ ${ }^{2}$ Inner Mongolia Center for Tuberculosis Control and Prevention, Huhhot, China \\ ${ }^{3}$ Inner Mongolia Fourth Hospital, Huhhot, China \\ ${ }^{4}$ Fukushima Medical University School of Medicine, Fukushima, Japan \\ ${ }^{5}$ Inner Mongolia Center for Disease Control and Prevention, Huhhot, China \\ ${ }^{6}$ Inner Mongolia Autonomous Region Department of Health, Huhhot, China
}

Enbo $\mathrm{Ma}^{1 *}$, Liping Ren ${ }^{2 *}$, Wensheng Wang $^{3}$, Hideto Takahashi ${ }^{4}$, Yukiko Wagatsuma ${ }^{1}$ Yulin Ren², Fei $\mathrm{Gao}^{2,3}$, Fangfang $\mathrm{Gao}^{2,3}$, Wenrui Wang ${ }^{5}$, and Lifu $\mathrm{Bi}^{6}$

Received February 6, 2014; accepted December 2, 2014; released online March 21, 2015

Copyright $(0) 2015$ Enbo Ma et al. This is an open access article distributed under the terms of Creative Commons Attribution License, which permits unrestricted use, distribution, and reproduction in any medium, provided the original author and source are credited.

\begin{abstract}
Background: The aim of this study is to evaluate the awareness status, attitudes, and care-seeking behaviors concerning tuberculosis (TB) and associated factors among the public in Inner Mongolia, China.

Methods: A five-stage sampling was conducted, in which counties as the primary survey units and towns, villages, and households as sub-survey units were selected progressively. A standardized questionnaire was used to collect TB information. Complex survey analysis methods, including the procedures of survey frequency and survey logistic regression, were applied for analysis of TB knowledge and associated factors. The sample was weighted by survey design, non-respondent, and post-stratification adjustment.

Results: Among 10581 respondents, awareness that TB is an infectious disease was $86.7 \%$. Knowing that a cough lasting $\geq 3$ weeks is suggestive of TB was $26.9 \%$. Knowledge about TB dispensaries in county administrative areas was reported by $68.3 \%$ of respondents, and knowledge about the free TB detection/treatment policy was reported by $57.5 \%$ of respondents. About $52.5 \%$ of participants would stigmatize TB patients. Compared with the majority Han ethnic group, Mongolians and other minorities were 1.52-2.18 times more likely to know about TB curability, TB symptoms, the free detection/treatment policy, and TB dispensaries' locations, but were less likely to know about the TB transmission mode (odds ratio, $0.74 ; 95 \%$ confidence interval, $0.65-0.84$ ). The main sources of TB information were TV (65.6\%) and other persons (47.2\%). In the past year, 19.7\% of TB knowledge was from acquaintances, and $16.1 \%$ was from TB institutes.
\end{abstract}

Conclusions: Improvement in knowledge about TB risk (symptoms and transmission), the free treatment policy, and facilities is necessary and should be provided through effective multimedia for different target populations.

Key words: tuberculosis; knowledge; ethnic groups; media source; China

\section{INTRODUCTION}

China has the second largest tuberculosis (TB) epidemic in the world, with an estimated annual incidence of 1.30 million cases and 160000 deaths, and the prevalence of pulmonary TB in 2000 was 367 per 100000 people. ${ }^{1}$ Knowledge about $\mathrm{TB}$ and awareness of medical assistance are important for the success of TB control and prevention. ${ }^{2,3}$ Delays in TB case detection and treatment are associated with lack of $\mathrm{TB}$ knowledge, poor attitudes toward personal health, traditional beliefs and cultural factors, inability to access affordable healthcare services, and fear of stigmatization. ${ }^{4-9}$

Inner Mongolia is a multi-ethnic, geographically vast region and has the third-worst TB prevalence in China. The 4th national TB survey showed that the prevalence of TB and smear-positive TB was 612 and 146.4 per 100000 people in Inner Mongolia in 2000, respectively. ${ }^{10}$ China issued a 10-year National TB Control Plan (2001-2010), aiming to 
achieve $80 \%$ TB awareness among the public, $90 \%$ training of TB prevention techniques among village doctors, and 100\% involvement in TB prevention and treatment by medical institutes. ${ }^{1,2}$ Since then, a series of health promotion activities have been carried out, including a campaign to spread knowledge about TB using posters and commercials on TV and in other media. ${ }^{2}$ To monitor the progress of the implementation, Inner Mongolia participated in a national population-based cross-sectional study on knowledge, attitudes, and practices (KAP) concerning TB in public in 2006. ${ }^{11}$ Information about TB knowledge at the national level was published by the Chinese Center for Disease Control and Prevention (China CDC); however, information about Inner Mongolia, the region with the largest population of Mongolians in China, has not been reported.

The present study aimed to estimate the level of knowledge, attitudes, and health-seeking behaviors concerning TB among the public and to examine how those are affected by demographic, socioeconomic, and policy factors in Inner Mongolia. This study can serve as baseline information of TB knowledge among the public for monitoring the achievement of health promotion and TB control programs in Inner Mongolia in the future.

\section{METHODS}

\section{Study population and sampling}

Participants were residents of Inner Mongolia aged 12 to 65 years who had lived at their present residence for more than six months before the survey started. In the survey, a fivestage sampling scheme was adopted, following the framework of the 'Third National Health Service Survey'. 2,12 In brief, 101 counties in Inner Mongolia were first categorized into 3 groups based on their gross domestic product (GDP) in 2005 $(<185 / 185-370 />370$ million USD); then, 3 counties were randomly selected from each GDP group. Further, through a systematic randomized method, 2 towns from each county, 3 villages/communities from each town, and 100 households from each village/community were selected, step by step. Finally, from each selected household, two individuals were chosen whose birthdays were closest to the interview date. Unsuccessfully interviewed subjects, such as those who missed visits three times, were replaced by individuals within five years' age difference, who were from the nearest non-sampled villages (eFigure 1).

\section{Questionnaire}

The standardized questionnaire from the national survey included information on demographic and socioeconomic characteristics (age, sex, ethnicity, education, occupation, economic area, marital status, health insurance, and family income in the past year), knowledge, attitude, and related careseeking behavior concerning TB (27 questions), as well as questions on how TB information was received, from which sources, and what the favorite TB information they received was.

The validity of the questionnaire was established through content and expert validity. ${ }^{2}$ Participants were interviewed by investigators from local CDCs and TB dispensaries who were intensively trained at the provincial level. ${ }^{2}$ Twenty percent of questionnaires from each sampled village/community were randomly selected for verification, and $5 \%$ of questionnaire responders were re-interviewed at their household by the investigators from the provincial CDC. The study was approved by the China National Ethics Committee of Operational Research on TB and the Inner Mongolia Department of Health.

\section{Data analysis}

In total 10800 questionnaires were delivered to the selected study subjects. The response rate was 98.2\%. From 10604 collected questionnaires, 23 questionnaires with systematic errors were excluded, leaving 10581 subjects for final analysis.

The internal consistency of TB knowledge outcomes were tested by Cronbach's alpha, which included the overall awareness of $\mathrm{TB}$ as an infectious disease, that $\mathrm{TB}$ is transmitted by coughing/sneezing of TB patients, prolonged cough lasting three weeks or more being suggestive of TB, the curability of $\mathrm{TB}$, the free TB detection/treatment policy, TB dispensaries in the county and larger administrative area, and stigmatization of TB patients. The outcomes of TB knowledge (7 questions) were categorized as either correct or incorrect answers (including missing values). Complex survey data analysis methods were applied for the sample weighted by multiple sampling design, non-respondent rates, and poststratification adjustments. The sample design weights were estimated according to the 2000 Inner Mongolia census (eTable 1). The post-stratification weights were calculated from the percentages of combination cells of age (5 groups), sex (2 levels), ethnicity (3 categories), education (3 levels), and region ( 2 levels) from the census divided by the percentages of corresponding cells in the sample after being weighted by survey design and non-response rate. ${ }^{13,14}$

Survey logistic regression models were applied to measure associations between each TB knowledge outcome and demographic and socioeconomic factors, with adjusted odds ratios (ORs) and 95\% confidence intervals (CIs) presented. In addition, one point was given for each correct answer to measure the overall knowledge acquired. ${ }^{15}$ The proportions and means of outcomes were computed by weighted samples. All analysis procedures were conducted after stratifying by GDP levels and clustering by counties, towns, villages, and households. Survey variances were estimated by the Taylor series variance method. All analyses were performed using SAS 9.31 statistical software (SAS Institute, Cary, NC, USA). All $P$ values reported were two-sided and the significance level was set at $<0.05$. 
Table 1. Characteristics of respondents in Inner Mongolia, China, in 2006

\begin{tabular}{|c|c|c|c|c|c|}
\hline Characteristics & $\begin{array}{l}\text { Unweighted } \\
(n=10581)\end{array}$ & $\%$ & $\begin{array}{c}\text { Weighted } \\
(n=23323349)\end{array}$ & $\begin{array}{c}\% \text { weighted } \\
\text { sample }\end{array}$ & $\begin{array}{l}\% 2000 \\
\text { Census }\end{array}$ \\
\hline \multicolumn{6}{|l|}{ Age groups, years } \\
\hline $12-19$ & 1118 & 10.6 & 2840912 & 12.2 & 12.3 \\
\hline $20-29$ & 1688 & 16.0 & 4824839 & 20.7 & 21.0 \\
\hline $30-39$ & 3067 & 29.0 & 5133085 & 22.0 & 22.2 \\
\hline $40-49$ & 2539 & 24.0 & 5471124 & 23.4 & 23.3 \\
\hline $50-65$ & 2169 & 20.5 & 5053389 & 21.7 & 21.2 \\
\hline \multicolumn{6}{|l|}{ Sex } \\
\hline Male & 5358 & 50.6 & 12534148 & 53.7 & 53.7 \\
\hline Female & 5223 & 49.4 & 10789201 & 46.3 & 46.3 \\
\hline \multicolumn{6}{|l|}{ Area } \\
\hline Urban & 3481 & 32.9 & 13709366 & 58.8 & 57.4 \\
\hline Rural & 7100 & 67.1 & 9613983 & 41.2 & 42.6 \\
\hline \multicolumn{6}{|l|}{ Ethnicity } \\
\hline Han & 7478 & 70.7 & 18481541 & 79.2 & 79.2 \\
\hline Mongolian & 2456 & 23.2 & 3955920 & 17.0 & 17.1 \\
\hline Other & 647 & 6.1 & 885888 & 3.8 & 3.7 \\
\hline \multicolumn{6}{|l|}{ Education } \\
\hline Elementary school and below & 3836 & 36.3 & 5268097 & 22.6 & 22.9 \\
\hline Junior school & 4477 & 42.3 & 10341283 & 44.3 & 44.5 \\
\hline High school and above & 2268 & 21.4 & 7713969 & 33.1 & 32.6 \\
\hline \multicolumn{6}{|l|}{ Marital status } \\
\hline Married & 8650 & 81.7 & 18083837 & 77.5 & - \\
\hline Unmarried/Divorce/Widow & 1931 & 18.3 & 5239512 & 22.5 & - \\
\hline \multicolumn{6}{|l|}{ Occupation } \\
\hline Administration and management & 333 & 3.1 & 1167748 & 5.0 & - \\
\hline Health care & 139 & 1.3 & 404986 & 1.7 & - \\
\hline Education & 231 & 2.2 & 698062 & 3.0 & - \\
\hline Professional technician & 285 & 2.7 & 1166451 & 5.0 & - \\
\hline Commercial and services & 379 & 3.6 & 1276332 & 5.5 & - \\
\hline Factory worker & 766 & 7.2 & 3011198 & 12.9 & - \\
\hline Farming & 6188 & 58.5 & 8826486 & 37.8 & - \\
\hline Student & 940 & 8.9 & 2824724 & 12.1 & - \\
\hline Unemployed & 1320 & 12.5 & 3947362 & 16.9 & - \\
\hline \multicolumn{6}{|l|}{ Medical insurance } \\
\hline Self-payment & 6492 & 61.3 & 14195032 & 60.9 & - \\
\hline Have insurance & 4028 & 38.1 & 9008295 & 38.6 & - \\
\hline Other & 61 & 0.6 & 120022 & 0.5 & - \\
\hline \multicolumn{6}{|l|}{ Annual income, USD (tertile category) } \\
\hline$<736.2$ & 3420 & 32.3 & 5952064 & 25.5 & - \\
\hline $736.2-<1472.4$ & 3597 & 34.0 & 6884267 & 29.5 & - \\
\hline$\geq 1472.4$ & 3564 & 33.7 & 10487018 & 45.0 & - \\
\hline
\end{tabular}

USD, United States Dollar.

\section{RESULTS}

Table 1 shows the characteristics of 10581 unweighted and 23323349 weighted survey participants. The mean (standard error) age was $37.4(0.20)$ years. Farmers had lower income (44.6\% in the lowest category of family income) and less education $(41.9 \%$ in elementary or lower level) than other occupations. More than $28.8 \%$ of students were from rural areas. The percentage with health insurance was lower among farmers $(31.9 \%)$, commercial and service employees (25.1\%), and students $(20.8 \%)$ than among participants with other occupations. Compared with ethnic Han, minorities had lower education $(29.1 \%$ vs $20.9 \%$ in elementary school or lower and $22.2 \%$ vs $35.9 \%$ in high school or above; $P<0.001$ ), more rural residents $(71.5 \%$ vs $33.3 \% ; P<0.001)$, more residents with middle and fewer with high family income $(37.7 \%$ vs $27.4 \%$ and $24.3 \%$ vs $30.3 \% ; P<0.001$ ), more unmarried residents $(26.1 \%$ vs $21.5 \% ; P<0.001)$, and fewer with medical insurance $(23.9 \%$ vs $42.5 \% ; P<0.001)$.

\section{Knowledge of TB}

The Cronbach's alpha values for testing the internal consistency of TB knowledge outcomes were between 0.655 and 0.827 . Considering all respondents, 91.1\% had heard of TB and $86.7 \%$ knew TB is an infectious disease (Table 2). About $80.7 \%$ of respondents knew at least 1 TB symptom, $26.9 \%$ knew the suggestive TB symptom (cough), and $63.3 \%$ knew the TB transmission mode. More than $68.3 \%$ were aware of the existence of TB dispensaries in the county and larger administrative area, while $85.1 \%$ believed that TB could be partially or completely cured, and about $57.5 \%$ knew about the national policy of free TB diagnosis and treatment. 
Table 2. Knowledge, attitudes, and behaviors concerning TB in Inner Mongolia, China in 2006

\begin{tabular}{|c|c|c|}
\hline Statements & $\begin{array}{l}\% \text { weighted } \\
\text { sample }\end{array}$ & $95 \% \mathrm{Cl}$ \\
\hline Overall awareness of TB an infectious disease & 86.7 & $85.8-87.6$ \\
\hline \multicolumn{3}{|l|}{ TB symptom ${ }^{a}$} \\
\hline Know at least one symptom & 80.7 & $79.6-81.8$ \\
\hline Fever & 38.0 & $36.5-39.5$ \\
\hline Shortness of breath & 40.0 & $38.6-41.4$ \\
\hline Cough & 74.6 & $73.4-75.8$ \\
\hline Sputum & 48.6 & $47.2-50.1$ \\
\hline Hemoptysis & 24.2 & $22.9-25.5$ \\
\hline Chest pain & 16.3 & $15.2-17.3$ \\
\hline Loss of weight and fatigue & 27.9 & $26.6-29.2$ \\
\hline Night sweat & 17.4 & $16.2-18.6$ \\
\hline TB transmitted by cough/sneeze & 63.3 & $62.0-64.7$ \\
\hline Cough $\geq 3$ weeks is suggestive of TB & 26.9 & $25.6-28.2$ \\
\hline Prevention by avoiding close contact with TB patients & 59.5 & $58.1-60.9$ \\
\hline Vaccination for children can prevent TB & 63.8 & $62.5-65.2$ \\
\hline TB is a curable disease & 85.1 & $84.1-86.0$ \\
\hline \multicolumn{3}{|l|}{ Benefits from early detection and treatment of TB* } \\
\hline Cure earlier & 66.7 & $65.4-68.1$ \\
\hline Reduce cost & 44.4 & $42.9-45.8$ \\
\hline Prevent infection of others & 45.9 & $44.4-47.4$ \\
\hline TB dispensaries located at county-and-above level & 68.3 & $66.9-69.6$ \\
\hline Free TB detection/treatment policy & 57.5 & $56.0-59.0$ \\
\hline \multicolumn{3}{|l|}{ Attitudes to TB patients in neighborhood } \\
\hline Keep away & 52.5 & $51.0-53.9$ \\
\hline Interact as usual or give support & 32.1 & $30.7-33.5$ \\
\hline Willing to learn knowledge on TB prevention & 89.2 & $88.4-90.0$ \\
\hline Willing to attend community activities for TB control & 88.9 & $88.1-89.7$ \\
\hline Ever learned TB knowledge on one's own & 13.6 & $12.6-14.6$ \\
\hline Ever offered TB knowledge to others & 12.5 & $11.5-13.4$ \\
\hline
\end{tabular}

$\mathrm{Cl}$, confidence interval; $\mathrm{CDC}$, Center for Disease Control and Prevention; TB, tuberculosis.

aultiple choices.

Only $32.1 \%$ would give support to or treat their neighbors as usual if their neighbors suffered from TB. The rate of respondents who responded correctly to 2 key questions about TB knowledge (ie, the suggestive TB symptom of cough and the free TB detection/treatment policy) was $21.0 \% ; 19.9 \%$ correctly answered 3 key questions (also knowing about TB dispensaries in the county or larger administrative area). A total of $7.0 \%$ responded to all 7 outcome questions correctly.

About $88.9 \%$ of participants were willing to learn TB knowledge or to attend community activities for TB prevention and control; however, less than $13.6 \%$ of participants had ever learned from or provided others with the TB knowledge (Table 2).

\section{Knowledge in subpopulation}

TB knowledge scores were higher in residents who were male, resided in an urban area, were married, had medical insurance, or had higher family income (Table 3). Farmers, commercial and services employees, and students had lower TB knowledge scores than other occupations.

Compared to the $12-19$ years age group (78.2\% were students), participants aged 20-29 years were 1.44 times more likely to know of the TB free detection/treatment policy. Men were $15 \%-22 \%$ more likely than women to know the suggestive TB symptoms, transmission mode, treatment policy, and the location of TB dispensaries. Urban residents were $27 \%-94 \%$ more likely than rural residents to know about TB, except for the TB treatment policy. Married persons were $52 \%-91 \%$ more likely than others to have TB knowledge (except for knowledge of the suggestive TB symptoms).

Among occupations, health care workers were 3.48-4.39 times more likely than farmers to know the suggestive TB symptoms, treatment policy, and TB dispensaries. Commercial and service employees and factory workers were $50 \%-33 \%$ less likely to know about TB treatment policy than farmers. Compared with Han Chinese, minorities were 1.52-2.18 times more likely to have TB knowledge but $26 \%$ less likely to know about the TB transmission mode. These disparities in acquired TB knowledge among Han and minorities are shown in Figure 1.

The higher their education, the more TB knowledge participants had acquired (Figure 2). Adjusted ORs were 1.43-4.03 in participants who had junior high school education and above compared with those who had only elementary or lower education. Similarly, middle- and highincome families were 1.25-2.51 times more likely than lowerincome families to know about TB's infectiousness, curability, transmission mode, and TB dispensaries; but were $27 \%-17 \%$ less likely to know suggestive TB symptoms. In addition, participants who were from rural areas, had less education, or were farmers or professional technicians were more likely to stigmatize TB patients than participants in other groups.

\section{Sources of tuberculosis knowledge}

TV programs $(65.6 \%)$ and personal sources $(47.2 \%)$ were the main communication channels of TB knowledge, while less influential channels were TB campaigns or exhibitions (3.6\%), the internet $(4.4 \%)$, schools $(6.2 \%)$, and audiovisual products $(0.8 \%)$. Among persons who knew the suggestive TB symptom, the main sources were cassettes/tapes/CDs (53.1\%) and the internet (49.9\%), and the least influential source was from other persons $(26.5 \%)$. In participants knowing the TB treatment policy, the main sources were cassettes/tapes/CDs (86.4\%) and posters $(80.0 \%)$, and the least influential sources were schools $(66.8 \%)$ and other persons $(62.5 \%)$. Further, the main source in participants knowing about the locations of TB dispensaries was posters $(92.0 \%)$, and the least influential sources were schools (75.7\%) and other persons (72.0\%). TB knowledge obtained in the past year was almost equally obtained from family members, acquaintances, general medical settings, or TB institutes, which were more common sources than school teachers or schoolmates $(P<0.001)$. The favorite source of TB information varied $(P<0.001)$ (Table 4$)$.

\section{DISCUSSION}

It is evident that there are major gaps in knowledge about TB among demographic and socioeconomic groups in Inner 
Table 3. Multivariate odds ratios with $95 \%$ confidence intervals between tuberculosis knowledge and demographic and socioeconomic factors ${ }^{\mathrm{a}}$

\begin{tabular}{|c|c|c|c|c|c|c|c|c|}
\hline Factors & $\begin{array}{l}\text { Knowledge } \\
\text { score }{ }^{\mathrm{b}} \\
\text { mean (SE) }\end{array}$ & $\begin{array}{l}\text { TB is an infectious } \\
\text { disease }\end{array}$ & TB is curable & $\begin{array}{l}\text { Cough } \geq 3 \text { weeks is } \\
\text { suggestive of TB }\end{array}$ & $\begin{array}{l}\text { TB transmission } \\
\text { mode }\end{array}$ & $\begin{array}{l}\text { Free TB detection/ } \\
\text { treatment policy }\end{array}$ & $\begin{array}{l}\text { TB dispensaries in } \\
\text { county and larger } \\
\text { administrative area }\end{array}$ & $\begin{array}{l}\text { Do not stigmatize } \\
\text { TB patients }\end{array}$ \\
\hline \multicolumn{9}{|l|}{ Age groups, years } \\
\hline $12-19$ & $3.9 \pm 0.08$ & Ref & Ref & Ref & Ref & Ref & Ref & Ref \\
\hline $20-29$ & $4.6 \pm 0.06$ & $1.19(0.77-1.85)$ & $1.23(0.83-1.84)$ & $1.39(0.99-1.95)$ & $1.14(0.84-1.53)$ & $1.44(1.07-1.96) * * *$ & $1.36(0.99-1.88)$ & $1.33(0.97-1.82)$ \\
\hline $30-39$ & $4.5 \pm 0.04$ & $1.01(0.65-1.55)$ & $1.09(0.72-1.64)$ & $1.36(0.96-1.95)$ & $1.24(0.91-1.70)$ & $1.14(0.83-1.57)$ & $1.29(0.92-1.80)$ & $1.11(0.79-1.55)$ \\
\hline $40-49$ & $4.2 \pm 0.05$ & $0.79(0.51-1.23)$ & $0.81(0.53-1.22)$ & $1.31(0.93-1.87)$ & $1.26(0.92-1.73)$ & $1.03(0.75-1.41)$ & $1.00(0.72-1.40)$ & $1.13(0.81-1.59)$ \\
\hline $50-65$ & $3.8 \pm 0.06$ & $0.75(0.48-1.16)$ & $0.77(0.51-1.17)$ & $1.11(0.77-1.60)$ & $1.21(0.87-1.67)$ & $0.93(0.68-1.29)$ & $0.97(0.69-1.35)$ & $0.87(0.62-1.23)$ \\
\hline \multicolumn{9}{|l|}{ Sex } \\
\hline Female & $4.1 \pm 0.03$ & Ref & Ref & Ref & Ref & Ref & Ref & Ref \\
\hline Male & $4.3 \pm 0.03$ & $1.08(0.94-1.24)$ & $1.10(0.96-1.26)$ & $1.15(1.03-1.29)^{*}$ & $1.15(1.04-1.28)^{* *}$ & $1.22(1.11-1.34)^{*}$ & $1.22(1.09-1.35)^{*}$ & $1.01(0.91-1.12)$ \\
\hline \multicolumn{9}{|c|}{ 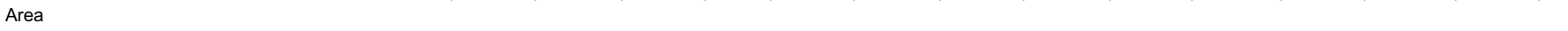 } \\
\hline Rural & $3.7 \pm 0.03$ & Ref & Ref & Ref & Ref & Ref & Ref & Ref \\
\hline Urban & $4.6 \pm 0.04$ & $1.81(1.38-2.38)^{*}$ & $1.88(1.45-2.42)^{*}$ & $1.94(1.61-2.34)^{*}$ & $1.27(1.07-1.50)^{* *}$ & $1.00(0.85-1.19)$ & $1.44(1.20-1.73)^{*}$ & $1.53(1.29-1.82)^{*}$ \\
\hline \multicolumn{9}{|l|}{ Ethnicity } \\
\hline Han & $4.2 \pm 0.03$ & Ref & Ref & Ref & Ref & Ref & Ref & Ref \\
\hline Mongolian and others & $4.3 \pm 0.04$ & $2.18(1.79-2.65)^{*}$ & $1.52(1.26-1.82)^{*}$ & $1.55(1.34-1.79)^{*}$ & $0.74(0.65-0.84)^{*}$ & $1.99(1.73-2.30)^{*}$ & $1.71(1.47-1.98)^{*}$ & $1.10(0.96-1.26)$ \\
\hline \multicolumn{9}{|l|}{ Education } \\
\hline Elementary school and below & $3.2 \pm 0.05$ & Ref & Ref & Ref & Ref & Ref & Ref & Ref \\
\hline Junior high school & $4.3 \pm 0.04$ & $2.10(1.77-2.51)^{*}$ & $2.00(1.68-2.38)^{*}$ & $1.43(1.21-1.69) *$ & $1.48(1.29-1.70)^{*}$ & $2.00(1.74-2.30)^{*}$ & $1.97(1.71-2.28)^{*}$ & $1.40(1.19-1.63)^{*}$ \\
\hline Senior high school and above & $4.8 \pm 0.05$ & $4.03(2.89-5.63)^{*}$ & $2.88(2.14-3.88)^{*}$ & $1.73(1.39-2.15)^{*}$ & $1.92(1.57-2.35)^{*}$ & $2.59(2.12-3.17)^{*}$ & $2.39(1.92-2.99)^{*}$ & $1.33(1.07-1.64)^{* *}$ \\
\hline \multicolumn{9}{|l|}{ Marital status } \\
\hline Single/divorce/widow & $4.0 \pm 0.06$ & Ref & Ref & Ref & Ref & Ref & Ref & Ref \\
\hline Married & $4.3 \pm 0.03$ & $1.91(1.44-2.53)^{*}$ & $1.80(1.35-2.39)^{*}$ & $1.03(0.81-1.31)$ & $1.52(1.23-1.87)^{*}$ & $1.56(1.24-1.96)^{*}$ & $1.55(1.23-1.95)^{*}$ & $1.03(0.82-1.30)$ \\
\hline \multicolumn{9}{|l|}{ Occupation } \\
\hline Farming & $3.7 \pm 0.04$ & Ref & Ref & Ref & Ref & Ref & Ref & Ref \\
\hline Administration and management & $4.9 \pm 0.10$ & $1.37(0.76-2.46)$ & $0.56(0.31-1.00)$ & $1.11(0.77-1.61)$ & $1.38(0.95-2.00)$ & $0.82(0.58-1.14)$ & $1.68(1.11-2.53)^{* * *}$ & $1.21(0.86-1.72)$ \\
\hline Commercial and services & $4.3 \pm 0.12$ & $0.89(0.54-1.46)$ & $0.64(0.40-1.04)$ & $1.19(0.84-1.67)$ & $1.00(0.72-1.38)$ & $0.50(0.37-0.68)^{*}$ & $0.76(0.55-1.06)$ & $1.30(0.94-1.79)$ \\
\hline Education & $5.0 \pm 0.12$ & $1.84(0.59-5.72)$ & $2.54(0.79-8.15)$ & $1.05(0.67-1.64)$ & $1.34(0.87-2.07)$ & $1.08(0.70-1.68)$ & $2.28(1.34-3.88)^{* *}$ & $1.16(0.78-1.72)$ \\
\hline Factory worker & $4.7 \pm 0.07$ & $1.46(0.89-2.40)$ & $0.92(0.60-1.41)$ & $1.02(0.78-1.33)$ & $1.36(1.05-1.77)^{* * *}$ & $0.67(0.52-0.86)^{* *}$ & $1.06(0.80-1.39)$ & $1.18(0.91-1.53)$ \\
\hline Health care & $5.5 \pm 0.13$ & $1.65(0.64-4.26)$ & $1.26(0.52-3.06)$ & $3.48(2.17-5.57)^{*}$ & $1.32(0.80-2.19)$ & $3.49(1.73-7.03)^{*}$ & $4.39(1.94-9.91)^{*}$ & $1.58(0.99-2.54)$ \\
\hline Professional technician & $4.6 \pm 0.11$ & $1.36(0.66-2.82)$ & $0.74(0.41-1.34)$ & $0.97(0.67-1.42)$ & $1.11(0.77-1.59)$ & $0.73(0.51-1.04)$ & $1.42(0.93-2.19)$ & $0.64(0.44-0.94)^{* * *}$ \\
\hline Student & $4.1 \pm 0.08$ & $0.92(0.59-1.43)$ & $0.90(0.60-1.36)$ & $1.52(1.08-2.16)^{* * *}$ & $1.52(1.12-2.06)^{* *}$ & $0.87(0.64-1.18)$ & $1.09(0.79-1.51)$ & $1.53(1.11-2.11)^{* * *}$ \\
\hline Unemployed & $4.5 \pm 0.07$ & $1.50(1.06-2.14)^{* * *}$ & $1.19(0.86-1.65)$ & $1.39(1.10-1.77)^{* *}$ & $1.48(1.19-1.83)^{*}$ & $0.88(0.71-1.08)$ & $1.18(0.94-1.49)$ & $1.33(1.07-1.66)^{* * *}$ \\
\hline \multicolumn{9}{|l|}{ Health insurance } \\
\hline No & $4.0 \pm 0.04$ & Ref & Ref & Ref & Ref & Ref & Ref & Ref \\
\hline Yes & $4.6 \pm 0.04$ & $1.51(1.24-1.84)^{*}$ & $1.96(1.61-2.39)^{*}$ & $1.48(1.27-1.72)^{*}$ & $1.29(1.13-1.47)^{*}$ & $1.05(0.91-1.20)$ & $1.27(1.09-1.48)^{* *}$ & $1.60(1.38-1.86)^{*}$ \\
\hline \multicolumn{9}{|l|}{$\begin{array}{l}\text { Annual income, USD (tertile } \\
\text { category) }\end{array}$} \\
\hline$<736.2$ & $3.5 \pm 0.06$ & Ref & Ref & Ref & Ref & Ref & Ref & Ref \\
\hline $736.2-<1472.4$ & $4.3 \pm 0.05$ & $2.15(1.78-2.60)^{*}$ & $2.01(1.67-2.42)^{*}$ & $0.83(0.69-0.99)^{* * *}$ & $1.39(1.21-1.61)^{*}$ & $1.08(0.92-1.27)$ & $1.37(1.17-1.60)^{*}$ & $1.22(1.03-1.44)^{* * *}$ \\
\hline$\geq 1472.4$ & $4.5 \pm 0.04$ & $2.51(1.99-3.17)^{*}$ & $2.23(1.79-2.78)^{*}$ & $0.73(0.60-0.89)^{* *}$ & $1.30(1.11-1.52)^{* *}$ & $0.96(0.81-1.14)$ & $1.25(1.05-1.49)^{* * *}$ & $1.14(0.95-1.36)$ \\
\hline
\end{tabular}

$\mathrm{Cl}$, confidence interval; OR, odds ratio; USD, United States Dollar; SE, standard error; TB, tuberculosis.

a Ref: reference. $* P<0.001, * * P<0.01, * * * P<0.05$, and otherwise not significant.

bTested by one-way ANOVA. All $P<0.001$ among each group of factors, except for ethnicities.

Mongolia. Although the overall awareness of TB in Inner Mongolia was above the contemporary target of the national TB control strategy, core knowledge about TB, such as the TB transmission mode, suggestive TB symptoms, and the national free TB detection/treatment policy, was less known $(<70 \%)$. Particularly, lower levels of TB knowledge were evident among farmers, students, rural residents, and those who had less education or lower income.

The highest priority of TB control is early diagnosis and treatment of infectious TB cases. ${ }^{7}$ More than two months' delay in TB diagnosis may increase the likelihood of developing smear-positive TB by seven- to eight-fold. ${ }^{16}$ Lack of sufficient awareness among the public of the symptoms and signs of TB is one of the factors responsible for treatment delay. ${ }^{6,15,16}$ Overall TB awareness among the public in Inner Mongolia was lower than the national average $(89.0 \%)^{2}$ and in Yangzhong, a rich county in the southeast of China $(92.1 \%),{ }^{17}$ but higher than in Gansu province $(68.7 \%){ }^{18}$ The core knowledge acquired in Inner Mongolia was higher than the national average $(11.3 \%$ for 2 key questions and $9.1 \%$ for 3 key questions) but similar to Gansu province $(23.1 \%$ for 2 key questions and $20.2 \%$ for 3 key questions). ${ }^{18}$ The awareness levels of TB policy and TB dispensaries in Inner Mongolia were higher than Xian (45.9\% aware of TB policy) ${ }^{19}$ and Yangzhong (39.2\% and 42.3\%) provinces. ${ }^{17}$ However, awareness in Inner Mongolia of TB symptoms and of transmission mode were higher than in Shanxi province $(13.9 \% \text { and } 55.4 \%)^{20}$ but lower than in Xian province $(48.4 \%$ and $90.7 \%) .{ }^{19}$

In this study, the overall level of awareness of TB infection was similar to the U.S. National Health Interview Survey in $\geq 18$-year-old household residents $(87.0 \%)$ between 2000 and $2005 .{ }^{13}$ In our study, the rate of responding correctly about the TB airborne transmission route $(63.3 \%)$ was similar to that in a study in Vietnam $(62.4 \%)^{15}$ and higher than in studies in the U.S. $(44 \%)^{21}$ and Serbia $(22.9 \%){ }^{22}$ Awareness of TB curability $(85.1 \%)$ was higher than in the U.S. study $(32.0 \%)^{21}$ and Vietnamese study $(74.0 \%)^{15}$ and similar to the rate in the Serbian study $(86.6 \%){ }^{22}$ The proportion of correct answers to all 7 outcome questions in our study was similar to the 
Awareness of TB infection

TB curability

Cough $\geq 3$ weeks suggestive of TB

Mode of TB transmission

Free TB detection/treament policy

TB dispensaries at county level

No stigmatization of TB patients

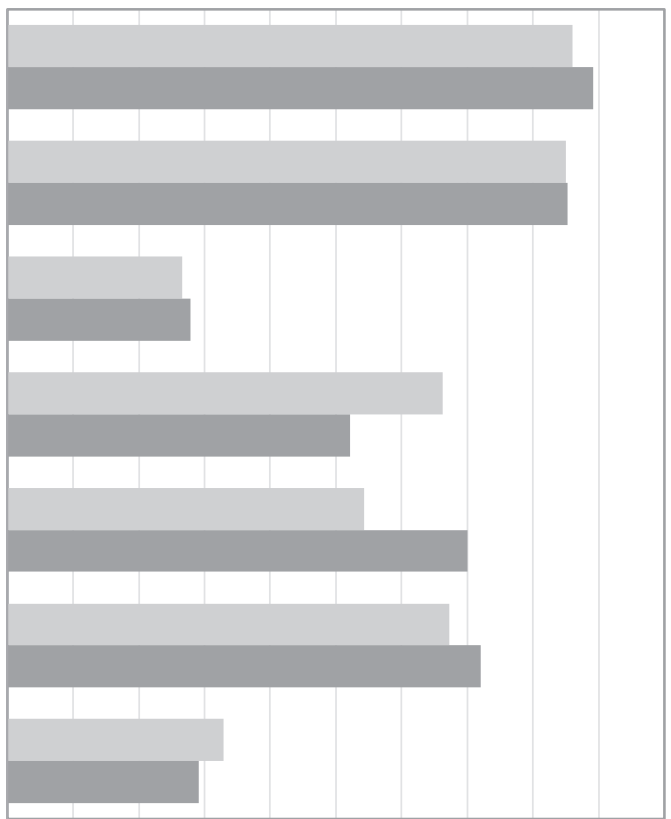

$\begin{array}{lllllllllll}0 & 10 & 20 & 30 & 40 & 50 & 60 & 70 & 80 & 90 & 100\end{array}$

Han Mongolian \& others

Figure 1. Tuberculosis (TB) knowledge among ethnicities

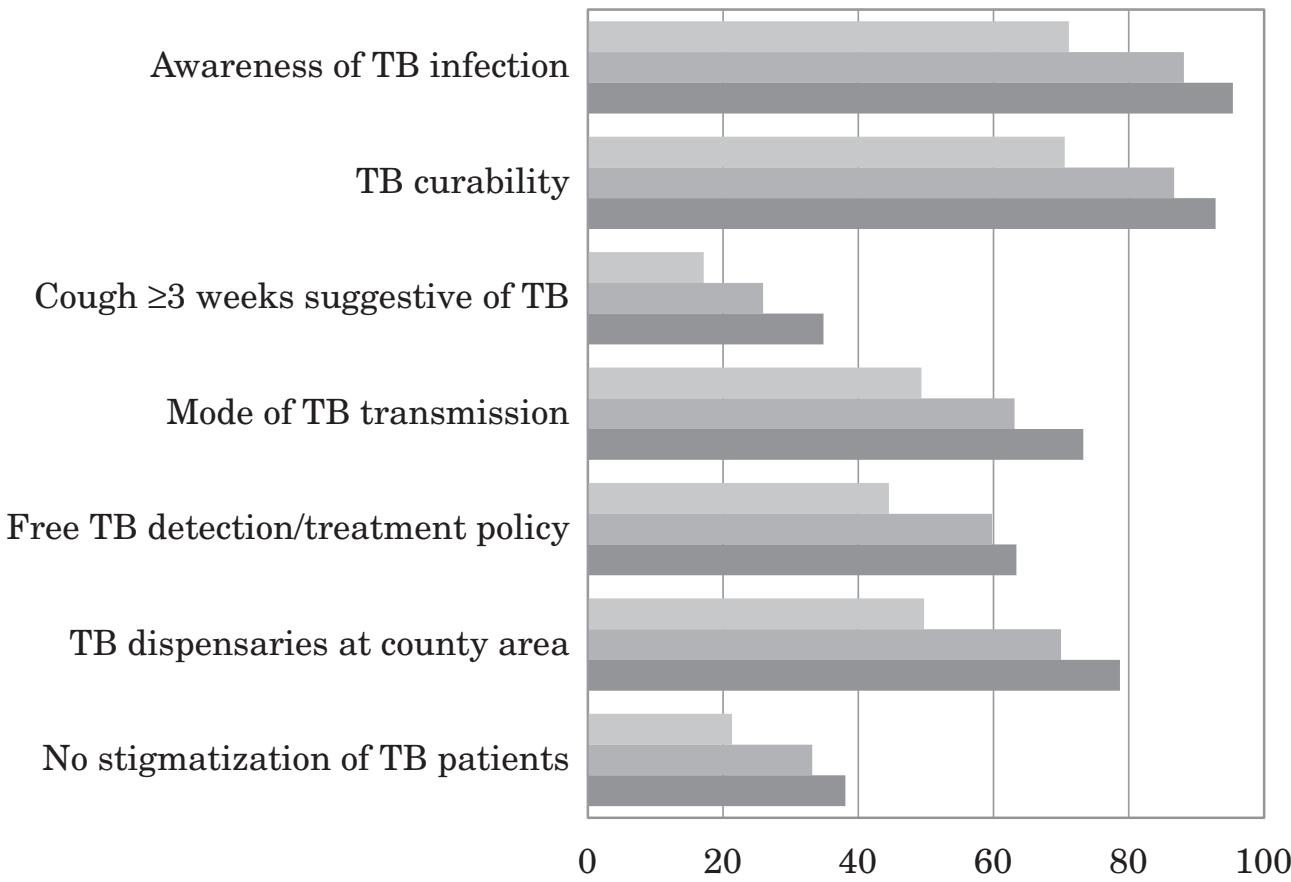

$\leq$ Elementary school $\square$ Junior high school $\square \geq$ Senior high school

Figure 2. Tuberculosis (TB) knowledge among educational levels

national average $(9.1 \%)^{2}$ and higher than in the Vietnamese survey $(4.4 \%){ }^{15}$

In our study, women, students, farmers, the unmarried, those with economic difficulties, and less educated people appeared to have less TB knowledge, which was similar to the results of other studies. ${ }^{2,17,20,23,24}$ Mongolians and other minorities were more likely than ethnic Han to know about the national policy of free TB treatment and about TB symptoms and curability but were less likely to know about the TB transmission mode. For TB transmission mode, about 34.0\% 
Table 4. Sources and communication channels of tuberculosis information

\begin{tabular}{lrc}
\hline & $\begin{array}{c}\text { \% weighted } \\
\text { sample }\end{array}$ & $95 \% \mathrm{Cl}$ \\
\hline Sources of TB knowledge & & \\
Broadcast & & \\
Newspaper/magazine/book & 33.4 & $32.0-34.9$ \\
Pamphlet/leaflet & 21.4 & $20.1-22.7$ \\
Television & 29.5 & $28.2-30.9$ \\
Campaign/exhibition & 65.6 & $64.2-67.0$ \\
Poster & 3.6 & $3.0-4.1$ \\
Internet & 16.7 & $15.6-17.9$ \\
Other person & 4.4 & $3.8-5.1$ \\
School & 47.2 & $45.8-48.6$ \\
Cassette/video tape/CD & 6.2 & $5.5-7.0$ \\
Source of TB knowledge last year ${ }^{\mathrm{a}}$ & 0.8 & $0.5-1.0$ \\
Family member or relative & & \\
Colleague/friend/neighbor & 15.7 & $14.6-16.8$ \\
School teacher/schoolmate & 19.7 & $18.5-20.9$ \\
Private/village/township/county hospital or clinic & 7.5 & $6.7-8.3$ \\
TB dispensary/local CDC/TB hospital & 16.8 & $15.8-17.7$ \\
Favorite TB information media & 16.1 & $15.1-17.1$ \\
Audio-visual materials & & \\
Witten materials & 13.0 & $12.1-13.9$ \\
Picture-based materials & 25.9 & $24.6-27.3$ \\
\hline
\end{tabular}

$\mathrm{Cl}$, confidence interval; CDC, Center for Disease Control and Prevention; TB, tuberculosis.

${ }^{\text {aMultiple choice. }}$

of minorities answered 'don't know' or 'not sure', which was higher than in Han respondents (17.6\%). This might be due to traditional beliefs about transmission of diseases in Mongolian ethnic groups, such as 'TB was inherited' and 'worked very heavily and drank cold water immediately after, causing the lung to split into pieces' ${ }^{23}$ It should be noted that Mongolians and other minorities were more likely to have lower education, be rural residents, be unmarried, and have no health insurance than Han respondents. In addition, the low rate of TB knowledge acquisition among commercial and service employees should also be given close attention. These phenomena might reflect the ineffective or insufficient coverage of TB information delivered by media and/or mass campaigns in Inner Mongolia. The rapid economic growth and urbanization in parts of Inner Mongolia and the increasing migrant population has led to a wider gap between urban and rural areas. ${ }^{25}$ It has been reported that the levels of knowledge and awareness of TB in TB suspects were lower in rural-tourban migrants than in residents. ${ }^{26}$ Nevertheless, more targeted TB control programs in different subpopulations need to be considered by policy-makers.

Diagnostic delay in the healthcare system may occur due to a lack of availability of services or low awareness of TB among healthcare workers. ${ }^{7}$ Surprisingly, only $57.1 \%$ of health employees in our study gave correct answers about the 3 key questions regarding TB knowledge, and $18.6 \%$ gave correct answers for all 7 TB knowledge questions, although their correct response rates were higher than among other respondents. In this study, about $25.4 \%$ of participants would initially visit various hospitals or clinics other than TB-related settings if they suspected TB infection. It has been reported that less educated, low-income, and old people were less likely to seek care at all or more likely to seek care at the village level than others. ${ }^{23}$ Training in TB knowledge for health workers in local medical settings needs to be strengthened, as they should remain vigilant and may reduce the TB diagnosis delay by regulating doctor referrals in TB control and prevention. ${ }^{17,24,27}$

Health-seeking behavior is not only decided by the KAP of individual patients, but also by socio-cultural determinants, such as stigma. ${ }^{6}$ Stigmatization can lead to further social isolation, delayed diagnosis, and poor adherence to therapy and can also contribute to a continued increase in TB incidence and the problem of drug resistance. ${ }^{28,29}$ In this study, $52.5 \%$ of participants were likely to keep their distance from TB patients, which was lower than the national average (71.9\%) but still high. ${ }^{2}$ Thus, health promotion campaigns to reduce social stigma by reinforcing the belief that TB is widespread and treatable should be implemented, along with improving TB knowledge among the public. ${ }^{2,28}$

The sources of TB information most commonly reported in our study were similar to those reported in the survey in Vietnam (64.6\% from TV and $42.7 \%$ from friends/relatives) ${ }^{15}$ As the coverage of TV programs and communications with acquaintances are high, these two ways of delivering or sharing TB information should be strengthened. However, for specific knowledge (eg, coughing for three weeks or more is suggestive of TB), TV programs and personal communications might not be the best way. In addition, the proportion of respondents receiving TB information in schools was very low. As modern technology develops, besides the current paper-based promotion materials, new and effective multimedia methods, such as the internet and audiovisual materials for campaigns or routine deliveries, are necessary. Such campaigns should include materials in minority languages and uncomplicated materials for less educated people. Inner Mongolia has made efforts and achieved substantial results in reducing the TB burden in the past decades. However, education of the public to achieve broad dissemination and pertinence of TB information through every possible means and in every possible venue, including the media, public health departments, and school systems, must go forward to continue TB control improvement. ${ }^{27}$ Without extensive public health education, the significant activities of the past years, which have dealt creatively with the reappearance of $\mathrm{TB}$, will diminish in importance.

\section{Limitations}

First, we used data from the 2000 Inner Mongolia census to calculate the sample design weights, due to the unavailability of information on administrative divisions and populations in selected towns, villages, and households in 2006. This may have resulted in slightly different estimations of weights and potential outcome variances in this study. Second, some lifestyle-related factors, such as smoking, alcohol drinking, and chronic disease history, were not 
collected for adjustment in the multivariate analysis. ${ }^{21}$ Third, we only used cough as the suggestive TB symptom in the analysis, although other signs and symptoms were mentioned in this study. ${ }^{2}$

\section{Conclusions}

The level of overall public awareness of TB in Inner Mongolia was higher than the contemporary national strategy target; however, core knowledge was still relatively low and showed disparities among ethnicities, occupations, and regions. The fundamental way to increase early $\mathrm{TB}$ care behavior is to increase TB knowledge among the public. Health promotion campaigns need to be regularly conducted using effective multimedia-based materials that suit different demographic groups (women, farmers, students, rural residents, minorities, and those with lower education). Further, similar studies need to be carried out to measure and monitor the changes in KAP when fulfilling national and regional TB control and prevention programs in Inner Mongolia.

\section{ONLINE ONLY MATERIALS}

eFigure 1. Flowchart on sampling process.

eTable 1. Sample design weights and non-response weight.

\section{ACKNOWLEDGEMENTS}

The authors are grateful for significant contributions to the data collection by the staff from Yuquan District Center for Disease Control and Prevention (CDC), Huhhot; Qingshan District CDC, Baotou; Chenbahu Banner CDC, Hulunbeier; Ewenke Autonomous Banner Tuberculosis Dispensary, Hulunbeier; Keerqinyouyiqian Banner Tuberculosis Dispensary, Xing'an; Shangdu County CDC, Jining; Zhuozi County CDC, Jining; Zhenglan Banner CDC, Xilinguole; and Hangjinhou Banner CDC, Bayannaoer. We thank Brian K. Purdue, Medical English Communications Center, University of Tsukuba, for excellent English revision.

E Ma and L Ren made equal contributions to this study, analyzed the data, and wrote the manuscript; L Ren, W-S Wang, and Y Ren, implemented this study; L Ren and Y Ren designed this study; and H Takahashi, Y Wagatsuma, F Gao, F-F Gao, W-R Wang, and L Bi critically reviewed and revised the manuscript.

Conflicts of interest: None declared.

\section{REFERENCES}

1. China Tuberculosis Control Collaboration. The effect of tuberculosis control in China. Lancet. 2004;364:417-22.

2. Lu SH, Tian BC, Kang XP, Zhang W, Meng XP, Zhang JB, et al. Public awareness of tuberculosis in China: a national survey of 69253 subjects. Int J Tuberc Lung Dis. 2009;13:1493-9.

3. Stop TB Partnership and World Health Organization. The Global
Plan to Stop TB, 2011-2015.

4. Shetty N, Shemko M, Abbas A. Knowledge, attitudes and practices regarding tuberculosis among immigrants of Somalian ethnic origin in London: a cross-sectional study. Commun Dis Public Health. 2004;7:77-82.

5. Godfrey-Faussett P, Kaunda H, Kamanga J, van Beers S, van Cleeff M, Kumwenda-Phiri R, et al. Why do patients with a cough delay seeking care at Lusaka urban health centres? A health systems research approach. Int $\mathrm{J}$ Tuberc Lung Dis. 2002;6:796-805.

6. Getahun H. Medical and social consequences of tuberculosis in rural Ethiopia. Ethiop Med J. 1999;37:147-53.

7. Chee CB, Gan SH, Chua AP, Wang YT. TB Control in Singapore: the high price of diagnostic delay. Singapore Med J. 2012;53:505-7.

8. Kurspahić-Mujčić A, Hasanović A, Sivić S. Tuberculosis related stigma and delay in seeking care after the onset of symptoms associated with tuberculosis. Med Glas (Zenica). 2013;10:272-7.

9. Ahmed Suleiman MM, Sahal N, Sodemann M, El Sony A, Aro AR. Tuberculosis stigma in Gezira State, Sudan: a case-control study. Int J Tuberc Lung Dis. 2013;17:388-93.

10. Inner Mongolia Tuberculosis Research Institute. Yearbook of tuberculosis control and prevetion in Inner Mongolia (2008). 2008:6.

11. The national tuberculosis epidemiology sampling technology steering group. The third national tuberculosis epidemiology sampling investigation report. Chin J Tuberc Respir Dis. 1992; 15:39-71.

12. Rao K, Chen Y, Chen X, Mao J. The sample design on selecting study setting in the national health statistic and special subject survey. Chin Health Stat. 1992;9:1-6.

13. Marks SM, Murrill C, Sanchez T, Liu KL, Finlayson T, Guilin V. Self-reported tuberculosis disease and tuberculin skin testing in the New York City House Ballroom community. Am J Public Health. 2008;98:1068-73.

14. Inner Mongolia Statistical Bureau. Inner Mongolia Census 2000. 2001.

15. Hoa NP, Chuc NT, Thorson A. Knowledge, attitudes, and practices about tuberculosis and choice of communication channels in a rural community in Vietnam. Health Policy. 2009; 90:8-12.

16. Cheng S, Chen W, Yang Y, Chu P, Liu X, Zhao M, et al. Effect of Diagnostic and Treatment Delay on the Risk of Tuberculosis Transmission in Shenzhen, China: An Observational Cohort Study, 1993-2010. PLoS One. 2013;8:e67516.

17. Wang J, Fei Y, Shen H, Xu B. Gender difference in knowledge of tuberculosis and associated health-care seeking behaviors: a cross-sectional study in a rural area of China. BMC Public Health. 2008;8:354.

18. Gan P, Wang B, Yang S, Xu M, Wang W, Zhang L, et al. Survey on awareness rate of tuberculosis control and prevention in the resident of Gansu Province. China Tuberculosis Control and Prevention. 2008;30:194-6.

19. Zhang X, Zeng L, Wang X, Du X, Han Y, Liu W, et al. A crosssectional survey of knowledge on tuberculosis in Xian City. China Tuberculosis Control and Prevention. 2008;30:2.

20. Li X. Analysis of survey on public knowledge, attitude and practice of tuberculosis prevention and control in Shanxi 
province. China Tuberculosis Control and Prevention. 2009;31: $126-9$.

21. Marks SM, Deluca N, Walton W. Knowledge, attitudes and risk perceptions about tuberculosis: US National Health Interview Survey. Int J Tuberc Lung Dis. 2008;12:1261-7.

22. Vukovic D, Nagorni-Obradovic L, Bjegovic V. Knowledge and misconceptions of tuberculosis in the general population in Serbia. Eur J Clin Microbiol Infect Dis. 2008;27:761-7.

23. Zhang T, Liu X, Bromley H, Tang S. Perceptions of tuberculosis and health seeking behaviour in rural Inner Mongolia, China. Health Policy. 2007;81:155-65.

24. Strand MA, Duan X, Johnson R, Li Y. Social determinants of delayed diagnosis of tuberculosis in a north China urban setting. Int Q Community Health Educ. 2010-2011;31:279-90.

25. Tobe RG, Xu L, Song P, Huang Y. The rural-to-urban migrant population in China: gloomy prospects for tuberculosis control. Biosci Trends. 2011;5:226-30.

26. Long Q, Li Y, Wang Y, Yue Y, Tang C, Tang S, et al. Barriers to accessing TB diagnosis for rural-to-urban migrants with chronic cough in Chongqing, China: A mixed methods study. BMC Health Serv Res. 2008;8:202.

27. Ailinger RL, Lasus H, Dear M. Americans' knowledge and perceived risk of tuberculosis. Public Health Nurs. 2003;20: 211-5.

28. Christodoulou M. The stigma of tuberculosis. Lancet Infect Dis. 2011;11:663-4.

29. Li Y, Ehiri J, Tang S, Li D, Bian Y, Lin H, et al. Factors associated with patient, and diagnostic delays in Chinese TB patients: a systematic review and meta-analysis. BMC Med. 2013;11:156. 